\title{
DESCRISTIANIZACIÓN Y LAICIZACIÓN: DOS CONCEPTOS EN UNA MISMA HISTORIA
}

\author{
Eduardo Cavieres Figueroa * \\ Pontificia Universidad Católica de Valparaiso \\ ecavieres@pucv.cl
}

Fecha de recepción: agosto de 2017 Fecha de aceptación: diciembre de 2017

Resumen: Este artículo se refiere a los antecedentes históricos del proceso de secularización actual así como sus relaciones con la modernidad y el liberalismo. A su vez, toma en cuenta el análisis de parte del pensamiento de Benedicto XVI sobre el particular. En lo esencial, se enfatiza el concepto de "laicidad positiva" del Papa emérito.

Palabras clave: Hecho religioso, modernidad, secularización, historia, Benedicto XVI.

* Eduardo Cavieres Figueroa es MA. History por la Universidad de Wisconsin Madison (USA), Ph.D por la Essex University (Inglaterra), director del Programa Estudios Iberoamericanos, PEI*sur de la Pontificia Universidad Católica de Valparaíso, profesor emérito de dicha Universidad y de la Universidad de Chile. Ha trabajado como profesor en EHEAL de la Universidad de París III, Sorbonne (2000-2003); profesor extraordinario de la Universidad Austral de Valdivia (Chile); profesor investigador en el Instituto Universitario de Estudios Latinoamericanos (IELAT) en la Universidad de Alcalá (España). Obtuvo también el Premio Nacional de Historia (Chile, 2008). Sus líneas de investigación giran en torno a la Historia social de la cultura, Historia económica, América Latina y Europa, desde el siglo XVI al XXI. Ha desarrollado estudios sobre historias comunes en Chile, Bolivia y Perú y codirigido publicaciones al respecto. Sus publicaciones abarcan una diversidad temática y cuenta con más de 60 títulos en el extranjero y cerca de 180 en Chile, en ambas situaciones, artículos, capítulos de libros, prólogos, entre otros. 


\section{DE-CHRISTIANIZATION AND LAICIZATION. TWO CONCEPTS, JUST ONE HISTORY}

AвSTRACT: This article deals with historical facts underlying the current secularization process including its relationship with modernity and liberalism. It also analyses part of the thought of Benedict XVI about this process, with an emphasis on his definition of "positive secularity".

KEYwORDs: Religious fact, modernity, secularization, history, Benedict XVI.

\section{Introducción}

- Qué es la historia religiosa? Como otras historias, esta se define a partir de la singularidad de aquello que se trata de especificar y, en este caso, es obvio que la singularidad de la historia religiosa es el hecho religioso. ¿Qué significa? ¿Cuál es el nivel de significación del hecho religioso en la vida histórica? A los historiadores siempre es más fácil dedicarse a estudiar campos más concretos como la vida económica, la vida política o incluso la vida cultural, lo que siempre supone, además, ciertos grados de racionalidad que separaría las esferas de la objetividad y de la subjetividad.

El hecho religioso tiene otras connotaciones. Confronta a la razón humana con cuestiones fundamentales sobre el origen y destino del mundo, el sentido de la vida, el problema del mal, la inmortalidad, el amor: "El hecho religioso es un fenómeno profundamente humano, dado que el hombre no puede desentenderse de estos problemas" (Barrio, 2006, p. 16). Nos pone en una situación límite entre la creencia y la no creencia, pero la negación, en este caso, está referida a algo que puede no creerse, pero que no puede refutarse como inexistente. No es un juego de palabras: la no creencia resulta precisamente de la existencia de la creencia. Esta creencia no es la creencia en una autoridad superior, civil o propiamente religiosa, es algo que 
se transfiere a los bordes y límites de lo que es la existencia humana y es muy difícil, por lo tanto, crear allí una frontera más o menos clara para apreciar un límite definido entre lo que es propiamente la historia civil y una historia de la humanidad pensada desde el hecho religioso.

En efecto, cuando hablamos de historia de la Iglesia, en el caso particular de la historia de la Iglesia Católica, Apostólica y Romana, hay una clara diferencia historiográfica que proviene del siglo IV d. C. con la Historia eclesiástica, la de Eusebio de Cesárea, historia eclesiástica porque fue escrita como Historia de la Iglesia, de la institución, ligada por cierto a la historia de la salvación. En el prefacio del libro II, el mismo Eusebio señalaba lo siguiente:

En el primer libro hemos expuesto con breves pruebas todos los detalles necesarios para el prefacio de la Historia eclesiástica: la divinidad del Verbo Salvador, la antigüedad de las afirmaciones de nuestra enseñanza y cómo la conducta evangélica de los cristianos es la más antigua; $y$, además, todo cuanto se refiere a la reciente aparición de Cristo, a su ministerio antes de la Pasión y a la elección de los apóstoles. (2008, p. 63)

Más adelante, en el libro $\mathrm{V}$, se hace referencia a un episodio en que Marco Aurelio César luchaba contra germanos y sármatas. Al hallarse agobiados por la sequía, una de sus legiones, la llamada Melitene, se postró para dirigir sus ruegos a Dios recibiendo su ayuda al provocarse un huracán y una fuerte lluvia que dispersó a los enemigos. Por ese motivo, Eusebio llegaría a enfatizar lo siguiente: 
Este relato aparece tanto en los escritores ajenos a nuestra doctrina que se dedicaron a escribir acerca del tiempo mencionado, como en los nuestros. No obstante, los historiadores de fuera, no familiarizados con la fe, explican el portento, pero no confiesan que sucedió gracias a las oraciones de los nuestros. Por su parte, los nuestros, amantes de la verdad, transmiten el hecho honradamente y sin malicia. (2008, p. 170)

Hoy en día, son diversos los problemas de la vida contemporánea en donde igualmente se contraponen miradas que provienen desde el análisis religioso de la vida social con otras que separan los ámbitos de lo propiamente humano de las explicaciones teológicas. Posiblemente, uno de los procesos, ya de larga duración, que exteriorizan más claramente este conflicto es el llamado proceso de secularización que viene acompañando la modernidad desde sus albores. En este trabajo, nos referimos a los antecedentes históricos de dicho proceso, visto desde la historia y por parte de historiadores, y a una nueva dimensión liberal de la situación reflexionada centralmente a partir de Benedicto XVI.

\section{La Mirada Histórica e Historiográfica}

\section{1 ¿Puede un historiador católico enseñar teoría de la historia? Historia e historiografía}

La pregunta tiene sus contenidos y los tiene porque la teoría de la historia intenta, precisamente, tratar de entender los procesos históricos, no solo en sus accidentes y superficialidades, sino también en cuanto al 
carácter de la historia y de la existencia humana. Este último es un elemento esencial: somos humanos, somos seres históricos y, por ello, cuando estudiamos historia no estamos estudiando los fenómenos de la naturaleza ni observando nuestra naturaleza desde fuera.

Cuando lo hacemos, estamos dentro del propio ámbito de estudio, somos parte de aquello que estudiamos y no es solo una parte de nosotros lo que se refleja en ese acontecer histórico, sino también aquello más incomprensible, que está dentro de nosotros, que surge y se manifiesta de diversas maneras. Aquello lo podemos llamar desde muchos puntos de vista y lo podemos estudiar también desde muchas perspectivas. En el pasado más lejano, a partir de la filosofía; durante la Edad media, a partir de la teología; muy fuertemente entre los siglos XVI-XVII vuelve a reaparecer la filosofía; la ciencia intenta también conocerle, en particular desde el siglo XIX en adelante cuando el método científico se va imponiendo definitivamente sobre otros, racionalizando no solo la experiencia histórica, sino también las causalidades que la van produciendo.

Para los historiadores, si son además creyentes, es más o menos natural tratar de hacer una especie de síntesis entre la vida histórica propiamente tal, posible de aprehender a través del conocimiento, con aquello que preocupa respecto a los fundamentos de la existencia y de la trascendencia de la vida. No hay grandes conflictos; pero desde el punto de vista de historiadores no creyentes, ese sí es un problema. ¿Cómo pueden entender la historia en profundidad si la visualizan solo desde lo relativamente posible de ser catalogado como objetivo? Podríamos divagar en extenso sobre estas consideraciones, pero en este artículo deseamos plantear el problema desde lo historiográfico y desde lo histórico; en ambos casos, desde un planteamiento central común: la modernidad y el proceso de descristianización, más comúnmente visto simplemente como secularización. 
En primer lugar, historiográficamente como descristianización; en segundo lugar, lo histórico, arrancando de lo anterior, la secularización.

En tiempos más recientes, comenzaron a surgir otras formas de ver la historia. Para ello se partió de la historiografía francesa de la década de los 60, en medio de los movimientos culturales de la Europa de post-guerra, desde las nuevas formas filosóficas, con Jean Paul Sartre y el existencialismo. También se basó en un racionalismo más práctico y desde la historia económica, por ejemplo, que comenzaba a estudiar y a entender la sucesión de los ciclos económicos. Su postura iba más allá de los dichos bíblicos de que el movimiento económico es un ciclo permanente entre los siete años de las vacas flacas seguidos por los siete años de las vacas gordas, y que para ello requería de modelos, de nuevos lenguajes, de una historia abierta hacia otras disciplinas. Lo interdisciplinario comenzó a ser muy importante y la Escuela de los Annales, ahora con Fernand Braudel a la cabeza, comenzó a recorrer una serie de etapas que condujeron la historiografía de la segunda mitad del siglo XX.

La primera etapa fue la historia demográfica; la segunda, la historia de la familia. Cuando se comenzó efectivamente a construir una historia de la familia que permitió conocer en mejor forma a quiénes fueron y cómo fueron nuestros antepasados, a partir de la reconstitución familiar, pero también a partir de visualizar la familia desde todos los puntos de vista, aquello significó algo muy interesante y que terminó muy apegado a la historia religiosa: ¿con qué estudiamos el pasado?, ¿cómo estudiamos a quiénes fueron y como vivían los hombres de París del siglo XVI, o los europeos en el siglo XVIII, o las sociedades, hombres y mujeres, blancos y castas, que ocuparon estos espacios de la América colonial?

La forma metodológica surgió desde la reconstitución familiar, pero las fuentes, los documentos más importantes para hacer esta reconstrucción 
surgieron desde la Iglesia, desde los archivos parroquiales de Europa y de América, todos pertenecientes al mismo sistema cultural. Surgieron una serie de situaciones que se fueron infiriendo de todas estas documentaciones. Aunque también surgió una primera gran discusión: si los archivos parroquiales se deberían leer solo como documentos civiles, de la vida cotidiana del pasado o si igualmente pudiesen leerse como documentos que expresaban algo que iba más allá de la puramente cotidiano; discusión que, evidentemente, nunca termina y sigue permaneciendo.

Michelle Vovelle, posiblemente uno de los historiadores franceses más distinguidos de la segunda mitad del siglo XX, marxista, fue un gran estudioso de la Revolución francesa y su redescubridor a través de una propia sección académica que fundó en la Universidad de París. No estuvo ajeno a estos cuestionamientos, a estos documentos, a estas preguntas, $y$ por ello también escribió sobre lo que a él le parecía que tenía que ver con las posibilidades que ofrecía el carácter de los archivos parroquiales. Pierre Chaunu había sostenido, por ejemplo, que los archivos parroquiales eran la aduana de la vida, allí estaban las entradas y salidas de los individuos que habían pasado por este mundo.

En tiempos de Vovelle, en los años 1980, la historia de la familia y el uso de estos archivos y de esta documentación para entender y comprender mejor la vida de nuestros antepasados, fue mucho más allá y fue sobrepasando las preguntas que se hacían hacia el cura o hacia la Iglesia del pasado. Además, se fueron deteniendo en las advocaciones, en los reconocimientos de la creencia en Dios y en la Iglesia, pero también en una gran preocupación por lo que viene después de la vida, por cómo se puede acceder a un lugar determinado fuera de esta vida, por ejemplo, al purgatorio. La Bolsa y la Vida, como la llamó Jacques le Goff, estudió cómo desde fines del siglo XI a comienzos del siglo XIII, la concepción 
del pecado y de la penitencia cambió profundamente, espiritualizándose e interiorizando, a tal punto que la gravedad del pecado comenzó a medirse por la intención del pecador:

El penitente debe explicar su pecado en función de su situación familiar, social, profesional, en función de las circunstancias y de su motivación. El confesor debe tener en cuenta esos parámetros individuales, y por lo que se refiere a la satisfacción, es decir, la penitencia, debe indagar el reconocimiento del pecador, discernir su contrición... Así queda abierto un nuevo frente: el de la introspección, que transformará lentamente los hábitos mentales y los modos de comportamiento. Aquellos son los comienzos de la modernidad psicológica. (1996, pp. 16-17)

Ni la historia demográfica, ni de la familia, ni ninguna otra historia, ni la sociología, ni el estudio de conflictos podían desarrollar, historiográficamente, el estudio de estos problemas. Su estudio surgió, a través de una década o más, mediante la historia de las mentalidades. Y, ¿cuál era el propósito de la historia de las mentalidades? Se ha señalado que fue una historia ambigua por naturaleza, pero se ha aceptado que se trataba de la búsqueda de la explicación de los comportamientos sociales, colectivos, subrayando que entre ello está la explicación del porqué la gente teme, cree, se comporta de tales formas o se organiza de cuales maneras y porqué hace de un sistema de creencias un sistema cultural propio.

¿Dónde podemos encontrar la explicación de esos comportamientos? La historia de las mentalidades trató de aclarar, como problema, que hay una división entre la historia resultante de actos concientes, únicos, trascendentes 
en el tiempo, y aquella que se configura en el inconciente, aquello que no podemos manejar, pero sí nos puede manejar. Dentro de esta relación entre conciente e inconciente, evidentemente todo aquello que tiene que ver con las creencias es muy importante.

Vovelle, estudiando testamentos, quiso visualizar cómo los comportamientos sociales fueron cambiando y transformándose en el tiempo. Si apeláramos a Braudel, se tratarían de cambios en la larga duración. En la medida que iba transcurriendo ese largo tiempo, Vovelle advirtió lo que llamó un proceso de descristianización de Occidente. En su estudio Piedad barroca y descristianización, publicado originalmente en 1973, se preguntaba por la evolución de las prácticas religiosas y, en particular, por las actitudes culturales relacionadas con la muerte.

Para medir este proceso y entender las posturas del cristiano frente a la muerte y el más allá, recurrió al análisis sistemático de nada menos que 31, 000 testamentos. ¿Qué datos pretendía aislar mediante el manejo de esta enorme cantidad de material seriado? Prestó atención, entre otros, a ciertas referencias de las personas que hacían sus testamentos: investigó de qué manera y con qué frecuencia mencionaban a los santos patrones protectores, qué número de misas disponían que se dijeran por su eterno descanso, de qué manera planeaban sus funerales y hasta las dimensiones y cantidad de cirios que debían emplearse para la ceremonia.

De igual forma, identificó un cambio significativo entre lo que llamó la "pompa barroca" de los funerales del siglo XVII y la modestia de los entierros que se acostumbraban efectuar un siglo después. En el proceso de interpretar esa masa estadística, cotejó las diferentes actitudes de los testadores, distinguió a nobles, artesanos y campesinos, y examinó los hábitos de los habitantes de las ciudades, los pueblos y las pequeñas aldeas. Además, analizó el lenguaje utilizado y, buscando el reflejo de un sistema de 
representaciones colectivas, su principal logro consistió en poder identificar una tendencia social hacia la secularización.

Asimismo, sugirió que la descristianización, iniciada desde antes y que comenzó a hacerse evidente en los años de la Revolución francesa, era parte de un proceso espontáneo que pertenecía a una tendencia más amplia en la misma dirección (paulatino decaimiento de prácticas y devociones, multiplicidad de misas, tipos de sepulturas, entre otros). Para alcanzar sus conclusiones, Vovelle debió penetrar en la mentalidad que definía las prácticas religiosas de una sociedad (Fernández \& Vaquero, 1982). Aunque también es interesante que, en pleno siglo XX, esa mentalidad estaba siendo interpretada por un hombre no creyente como lo fue Vovelle.

Preguntándose sobre la descristianización de la Ilustración, Vovelle recordaba que ya casi no existen historiadores que piensen que Francia era totalmente creyente en 1789 y que la Revolución había sido el origen de la descristianización contemporánea. A pesar de que prácticamente se evidencia que algunos gestos masivos de la práctica son inamovibles (sacramentos), la progresiva deserción de los conventos, las sucesivas crisis de vocaciones, la disminución de misas, de elección de sepulturas, de legados o de pertenencias a cofradías vistas a través de testamentos, serían indicios importantes para caracterizar el proceso aún cuando Vovelle dice haberse impresionado por la laicización de las fórmulas y el retroceso de la Virgen y de los santos protectores en las invocaciones de esos actos. A lo anterior se suma que:

(...) el análisis de las representaciones del más allá en los cuadros de los altares de las almas del purgatorio confirma el empobrecimiento del panteón de los intercesores tradicionales. Además disponemos del rico conjunto de investigaciones realizadas por M. Agulhon sobre 
la laicización de las cofradías meridionales, expresión tradicional no sólo de la sociabilidad sino también de la religiosidad. (Vovelle, 1985, pp. 281-282)

Como este es un problema de la ilustración, lo religioso se convierte en punto sensible y campo de batalla. Así lo expresaba Vovelle:

¿Podríamos, quizá, decir que este siglo nos ofrece en germen un alejamiento de las religiones establecidas...? Es difícil sondear los riñones y los corazones, sobre todo habida cuenta de la falta de instrumentos estadísticos para una sociología religiosa como los que posee la época contemporánea. (Vovelle, 1995, p. 22)

Para algunos se trataba del peso del cual tenía que sacudirse la historia para entrar efectivamente en una línea de progreso. Aunque después, la historia política e ideológica, a pesar de los dichos de Vovelle, encontró su mejor expresión en la Revolución francesa cuando surgió un Estado que tiene que ser laico. Pero en su momento terminó con un nuevo Imperio que siguió todos los rituales tradicionales, dejando allí el problema de la secularización.

En términos del consciente e inconciente, además de la historia de las mentalidades, en la historia psicológica o psicohistoria cabía también el problema de la descristianización. Un buen estudio al respecto, referido a Michoacán, relata lo acontecido a mediados de la década de 1930 en el pequeño poblado de Ario Santa Mónica, en donde se produjo una especie de estallido social que arremetió en contra de la iglesia saqueándola y destruyendo y quemando sus imágenes en la plaza, tras lo cual las gentes volvieron a entrar para bailar alrededor del altar. Las causas pudieron ser variadas, pero cuando comenzó a volver el orden y la 
calma, la acción fue descrita como un signo negativo que habría explicado un fuerte período de sequía experimentado en la región. Muy posteriormente, una antropóloga pudo interrogar a una de las personas que aún sobrevivía, la cual resumió la situación en que cuando ello había ocurrido ella era una niña y si había que bailar había que hacerlo, pero que ahora que era una mujer de edad, lo que le interesaba era estar en paz con Dios y prepararse para una buena muerte (Becker, 1997).

El ejemplo, discutido con Michelle Vovelle, visto también en los inciertos niveles conciente/inconciente, levanta preguntas complementarias: ¿dónde opera un fenómeno de descristianización colectiva?, ¿¿dónde opera si no es en el pensamiento que provoca transformaciones en lo que se cree y con ello en los comportamientos? El problema proviene de la dificultad de poder precisar los orígenes de estos fenómenos y sus causalidades (Cavieres, 1998). Existe en esto un proceso largo que efectivamente tiene que ver con un proceso de laicización, de laicidad. Se le llame descristianización o laicización, este es un fenómeno propio de la sociedad moderna, de la de los siglos XVI al presente.

Víctor Hugo tuvo sus propias inquietudes al respecto y, cuando escribió Los miserables, escribió también un "Prefacio filosófico" que nunca terminó, y en donde quiso poner toda la desgraciada historia de la novela en un contexto mayor. Siendo agnóstico, la quiso poner en términos religiosos para tratar de comprender por qué suceden los hechos, pregunta esencial de creyentes y no creyentes respecto a los intrincados términos de la historia. En dicho prefacio, Víctor Hugo planteaba lo que sucedía en las ciencias, en la tecnología, maravillándose por una verdadera explosión de las potencialidades humanas y de la racionalidad. Sin embargo, refiriéndose a un exsacerdote que no duda en dar su vida para socorrer a otros o a una madre (en términos genéricos) que perdiendo a su hijo, igual implora a Dios, ponía el problema a esta relación entre las creencias y el progreso de una secularización cada vez más fuerte y progresiva. 
Vargas Llosa ha dedicado un ensayo a la obra de Víctor Hugo. En este, nos recuerda el breve preámbulo del prefacio en que el francés caracterizaba la naturaleza de la ficción y sus relaciones con el mundo real:

Este libro ha sido compuesto de dentro hacia fuera. La idea engendra los personajes, los personajes producen el drama, y ésta es, en efecto, la ley del arte; poniendo como generador, en lugar de la idea, al ideal, es decir a Dios, se advierte que cumple la función misma de la naturaleza. El destino y en particular la vida, el tiempo y en particular este siglo, el hombre y en particular el pueblo, Dios y en particular el mundo, he aquí lo que he intentado poner en este libro, especie de ensayo sobre el infinito (...). (Vargas Llosa ([2004] 2009, pp. 132-133)

El propio Vargas Llosa, siguiendo a Hugo, escribió que "las pruebas de la existencia de Dios están en las limitaciones del conocimiento para resolver los enigmas que surgen precisamente a medida que la ciencia ensancha su radio de acción” (Vargas Llosa, 2009, p. 133).

\subsection{Modernidad, descristianización, cultura y sociedad}

En los siglos de la modernidad, desde el XV al XVIII, estos fueron problemas que, salvo intereses de las Cortes, de la propia Iglesia o de ambos, se encontraron estrechamente ligados a una relación eclesiástica comunitaria; de los miembros de la sociedad con Dios. Cuando Vovelle se refiere a la descristianización, está observando transformaciones en los comportamientos sociales como producto de fenómenos culturales que 
cambiaban los espacios de la vida privada y de la vida pública. Desde el siglo XIX, se trata de la historia de un proceso que los historiadores conocemos no con respecto a los orígenes del Estado Moderno, sino más bien a su consolidación. Estado Moderno en referencia a un nuevo orden de relaciones sociales en donde la Iglesia pierde posiciones frente al Estado reduciéndose a unos ciertos lugares más privados que públicos.

Desde el siglo XIX, en adelante, tenemos un Estado enfrentado a la Iglesia y tenemos un mundo occidental que vuelve a recoger sus raíces laicas de la Antigüedad. El conflicto cada vez es mayor y ello impone otras conductas, comportamientos, relaciones entre nuestros inconscientes y conscientes. Estas, a su vez, se van transformando en unas nuevas ideologías, penetrando en nuestras formas de pensar y reorientándose hoy en una nueva historia cultural, determinada no siempre por lo que pensamos o lo que queremos, sino por las ideas ambientales y el orden político.

¿Qué es lo que ha sucedido desde el siglo XIX en adelante? Se ha producido una inversión de los términos entre la vida privada y la vida pública en que esta última penetra más fuertemente que la primera. Se pueden citar debates al respecto, en particular, referidos a las ahora llamadas agendas valóricas que se traducen en las nuevas políticas públicas. Entre ellos, los serios debates respecto al peso del número, del peso demográfico, y por ello las preocupaciones respecto a los controles demográficos que tienen que ver con la vida privada y los comportamientos dentro de esta, pero que en la realidad concreta están dirigidos desde la vida pública.

Desde la Fundación Rockefeller de los años 1960, y más abiertamente desde los Estados, posteriormente, el peso del número y los cambios en la estructura demográfica, sin negar conceptos sobre la existencia humana o de sus trasfondos religiosos, han impuesto una tendencia de descristianización de la vida. De igual forma, han implantado un concepto 
laico y económico de cómo la sociedad puede potenciar sus capacidades sexuales disminuyendo sus capacidades reproductivas. El objetivo final: una mejor distribución de los recursos disponibles, aún cuando en los mapas de la pobreza y la riqueza actual ello no solo sigue siendo objetivo muy lejano sino que, además, no muestra tendencias firmes en cuanto a una inversión objetiva, clara y específica de los índices de desigualdades existentes. A veces se trata solo de una cuestión de poder.

¿Cómo entender los siguientes procedimientos que se ordenaban para aplicar determinadas políticas públicas? Al respecto, resultan muy esclarecedoras las instrucciones entregadas por la jerarquía nazi para el control de la población que nos ha transcrito el historiador Pierre Chaunu:

Se debe inculcar a la población rusa por todos los medios de la propaganda, en particular por la prensa, la radio, el cine, los volantes, folletos y conferencias, que un gran número de hijos no representa sino una carga pesada. Hay que insistir en los gastos que ocasionan los hijos, en las buenas cosas que podrían tenerse con el dinero que se gasta en ellos. Se podría asimismo aludir a los peligros que para la salud de la mujer pueden representar los partos (...). Al mismo tiempo, se debe establecer una propaganda amplia y poderosa a favor de los productos anticonceptivos. Se debe crear una industria apropiada con este objeto. La ley no castigará ni la difusión, ni la venta de los productos anticonceptivos, ni tampoco el aborto. Habrá que facilitar la creación de instituciones especiales para el aborto, entrenar a esto a parteras o enfermeras. La población acudirá con más frecuencia a los servicios de abortos si éstos son efectuados 
con cuidado. Los médicos deben participar sin que eso atente contra su honor. La propaganda debe recomendar igualmente la esterilización voluntaria ${ }^{1}$. (Wetzel citado en Chaunu, [1979] 1982, p. 212)

En una primera lectura, en gran parte se trata de un discurso bastante actual, una política altruista. Si lo miramos históricamente y vemos sus propósitos como parte de las políticas del nacionalsocialismo de Hitler, nuestra impresión es otra. En una u otra situación, se soslaya el problema de fondo.

La cultura hoy en día, especialmente desde la historiografía respectiva, es también comportamiento. Hoy en día, cultura es igualmente formas de vivir, de comer, de amar, formas de sexualidad. Los términos del concepto son muy amplios y se ha despojado del refinamiento que tenía 40 o 50 años atrás. Desde estos ámbitos de la cultura, muchos fenómenos religiosos se han transformado en fenómenos culturales. Recientemente, el diario La Tercera (Santiago de Chile), ha publicado una de tantas encuestas del presente, la de un Programa de Servicios Internacionales de la Universidad de Chicago que se inició en 1991 y que, a partir de una simple pregunta (“¿Cree Ud. en Dios?”), efectuó mediciones a lo largo de todo el mundo en los años 1998 y 2008. No se relacionaba con iglesias particulares, sino con una idea general sobre cómo sentimos a Dios.

Los resultados mostraron que el país que más cree en Dios es Filipinas con un $86 \%$ y que Chile está en segundo lugar, con un $79.4 \%$ (ver Tabla 1). Si se recorren los resultados de otros países, aparentemente bajan las creencias religiosas, pero en realidad ellas siguen estando latentes: no se

1 Texto del Dr. Wetzel a petición de Himmler con respecto a las poblaciones de los territorios rusos que se conquistarían en el Este: genocidio de retardo. 
está hablando de un comportamiento puramente social o cultural, sino de un problema religioso. En todo el mundo, tal como la niñita de Michoacán que cuando se convierte en adulta se preocupa de su relación con Dios, la gente que tiene sobre los 50 años expresa un alto porcentaje de creencia en Dios. Por edades, entre los 30 y los 50 años son muy pocos, pero desde allí en adelante Dios comienza a recuperar su lugar ${ }^{2}$. ¿Hecho religioso? Difícil de explicar con lógicas del presente.

Tabla 1

Porcentaje de Creyentes y no Creyentes según Encuestas 1998 y 2008

\begin{tabular}{cccc}
\hline \multicolumn{2}{c}{ \% que no duda en la existencia } & \multicolumn{2}{c}{$\%$ que no cree en Dios } \\
\hline Filipinas & 83.6 & Este de Alemania & 52.1 \\
Chile & 79.4 & República Checa & 39.9 \\
Israel & 65.5 & Francia & 23.3 \\
Polonia & 62 & Holanda & 19.7 \\
Estados Unidos & 60.6 & Suecia & 19.3 \\
Chipre & 59 & Letonia & 18.3 \\
Portugal & 50.9 & Gran Bretaña & 18 \\
Irlanda del Norte & 45.6 & Dinamarca & 17.9 \\
Irlanda & 43.2 & Noruega & 17.4 \\
Italia & 41 & Australia & 15.9 \\
& & Hungría & 15.2 \\
\hline
\end{tabular}

Nota. Adaptado de "Estudio en 30 países muestra a Chile como el segundo que más cree en Dios," por C. Cifuentes Diario, 2012, La Tercera. Recuperado de www.imocorp.com.mx/ imo2/index.php/encuestas/difusion/menu-difusion-encuestas-issp/176-publicacion-2016-15.

2 La Tercera, 27 de mayo del 2012. 
A partir de las cifras, poco podría decirse de la descristianización, pero no en cuanto a la secularización. Si seguimos los estudios de Vovelle para la sociedad tradicional, y sus modificaciones respecto a formalidades de la vida religiosa, es cierto que se habrían producido importantes transformaciones en cuanto a las formas, pero no necesariamente respecto al fondo de los sentimientos religiosos. Desde allí en adelante lo que se produciría sería el inicio de un proceso de laicización y en ello se pasa desde el sujeto central, individuo, a un ente superior directo: el Estado.

\section{El Problema en Dimensiones Actuales: Liberalismo, Laicización, Estado e Iglesia}

En las últimas décadas, al menos en el mundo occidental, nos hemos acostumbrado a un nuevo concepto de modernización que marcha muy en relación a nuevos contenidos que se le han asignado al concepto tradicional de liberalismo. Este liberalismo, que pasó desde sus significados originales basados en los derechos naturales del hombre, a un recargado peso de elementos provenientes de la economía, ha vuelto a remozarse. Con ello, ha agregado ahora cuestiones que tienen que ver con una agenda valórica, moderna, se dice, en donde el Estado, permitiendo más que restringiendo, cambia nuevamente las relaciones entre las vidas privadas y públicas.

Cabe recordar el conocido diálogo entre Jürgen Habermas y Joseph Ratzinger, celebrado en la Academia Católica de Baviera en enero del 2004. Reflexionando sobre dogma y discurso y sobre ética católica y ética de la secularización occidental, Habermas proponía:

(...) entender la secularización cultural y social como un doble proceso de aprendizaje que lleve tanto a las 
tradiciones de la Ilustración como a las doctrinas religiosas a reflexionar acerca de sus límites... [señalaba que] el liberalismo político —que yo defiendo bajo la forma específica del republicanismo kantiano- ha de entenderse como una justificación no religiosa y post-metafísica de los fundamentos normativos del Estado constitucional democrático... [y agregaba] si lo entiendo bien, el punto de vista católico que acepta sin problemas el lumen naturale - no se opone en lo esencial, a una fundamentación autónoma de la moral y del derecho, es decir, en forma independiente de las verdades de la Revelación. (Barrio, 2006, pp. 144-146)

$\mathrm{Al}$ respecto, interesan los argumentos de Ratzinger. Estos se basaban, fundamentalmente, en un análisis de la ciencia y sus falsas contradicciones con la fe y el humanismo:

(...) estamos ante el despliegue de ciertas potencialidades humanas, creativas y destructivas, que llevan a replantear con inusitada agudeza el tema del control jurídico y ético del poder (...) Por otro lado, es incuestionable que el cambio fundamental en la imagen del hombre y del mundo propiciado por el desarrollo de la ciencia ha tenido un papel esencial en la ruptura de las antiguas convicciones morales (...) Se plantea, por una parte, la cuestión del origen del Derecho y, por otra, también la cuestión sobre sus propias dimensiones (...) Las mayorías pueden ser ciegas o injustas. La historia nos lo dice con absoluta claridad. Si una 
mayoría suficientemente grande oprime a una minoría con leyes represivas, por motivos religiosos o racistas, ¿puede hablarse entonces realmente de justicia o de Derecho? (...) [En otro plano], el hombre ahora es capaz de fabricar hombres, es decir, de producirlos in vitro. El hombre se convierte así en producto, y con ello se altera radicalmente la relación del hombre consigo mismo. Ya no es regalo de la Naturaleza, del Dios creador; él es su propio producto (...) [En la suma de estos y otros problemas, haciéndose eco de Kart Hübner, podría decirse que se trata de] que nos libremos de la representación, tremendamente falsa, de que la fe no tiene ya nada más que decir a los hombres de hoy, pues contradice la idea humanista de la Razón, de la Ilustración y de la Libertad. De este modo, yo hablaría de la necesidad de una relación mutua entre la razón y la fe, la razón y la religión, que están llamadas a una recíproca purificación y salvación, y recíprocamente se necesitan, al igual que tienen que reconocerse solidariamente. (Barrio, 2006, pp. 161-168; 175-176)

Llevada la situación al panorama político europeo, es muy cierto que las dos sociedades más relacionadas a un fuerte laicismo, a partir de Estados igualmente fuertes, han sido Francia e Inglaterra. Por diversas razones, o el peso de un republicanismo estatal o un Estado ligado a una Iglesia propia, allí han surgido parte importante de las reflexiones sobre el particular o de las decisiones que afectan la situación en el presente. Por ello mismo es que, los esfuerzos de Ratzinger, luego Benedicto XVI, por tratar de reorientar los verdaderos causes de la relación entre Estado y conciencia 
religiosa, entre las fronteras de la vida pública y la vida privada, no pueden pasar desapercibidos.

Ya en el 2003, el jefe del Gobierno de Francia convocó a una Comisión de Reflexión sobre la aplicación del Principio de Laicismo en la República. Es cierto que, en gran medida fue una respuesta oficial a la búsqueda de mayores consensos entre el Estado y las instituciones francesas debido a una cada vez más creciente presencia de poblaciones islámicas. Aunque, igualmente, reflejaba las preocupaciones por definir más claramente los límites entre los ámbitos de las responsabilidades ciudadanas y las profesiones de fe de carácter religioso ${ }^{3}$. Asimismo, volvió a poner el tema central en el debate público. A partir de ello, un interesante ejemplo político y de búsqueda de síntesis histórica en la relación Iglesia-Estado, correspondió a las expresiones del entonces presidente francés Nicolás Sarkozy vertidas el 20 de diciembre del 2007 en la Basílica de Letrán en Roma. En dicha ocasión, el concepto central fue el de laicidad positiva: las religiones deben verse no como un peligro, sino como un bien. Para Sarkozy:

(...) nadie ha puesto en duda que el régimen francés de la laicidad sea hoy en día una libertad: la libertad de creer o de no creer, la libertad de practicar una religión y la libertad de cambiarse a otra, la libertad de no ser contrariado en la conciencia por prácticas ostentatorias, la libertad de los padres de dar a sus hijos una educación conforme a sus convicciones, la libertad de nos ser

3 El informe de la Comisión, conocido como Informe Stasi, fue firmado en París el 11 de diciembre del 2003. Promovía una nueva legislación que incluyera reglas de funcionamiento para los servicios públicos y empresas y asegurara la diversidad espiritual del país. 
discriminado por la administración en funciones a causa de sus creencias.

Francia ha cambiado mucho. Los ciudadanos franceses tienen convicciones más diversas que antaño. Desde entonces, la laicidad se afirma como una necesidad y, oso decirlo, como una oportunidad. Se ha convertido en una condición de la paz civil. Por ello, el pueblo francés ha sido, al igual que ardiente en la defensa de libertad escolar, ardiente en su deseo de prohibir signos ostentatorios en la escuela.

Al ser eso la laicidad, no sabría negar el pasado. La laicidad no tiene el poder de cortar a Francia de sus raíces cristianas. Lo ha intentado. No ha podido. Al igual que Benedicto XVI, considero que una nación que ignora la herencia ética, espiritual y religiosa de su historia comete un crimen contra su cultura, contra esa mezcla de historia, patrimonio, arte y tradiciones populares, que impregna muy profundamente nuestra manera de vivir y de pensar. Arrancar la raíz, es perder la significación, debilitar el cimiento de la identidad nacional, desecar más todavía las relaciones sociales que tanta necesidad tienen de símbolos de memoria. (Sarkozy, 2007)

Anteriormente, en diciembre del 2005, Benedicto XVI, a 40 años de la Gaudium et Spes, abogaba por una relación entre fe y razón en el contexto de las ciencias naturales e históricas; de la Iglesia con el Estado en el contexto de la libertad religiosa y la tolerancia de la vida civil; y de la fe cristiana con otras religiones en el contexto de la libertad religiosa. En 
el 2008, al visitar Francia por primera vez como jefe de la Iglesia Católica, refiriéndose a las expresiones ya citadas de Sarkozy, señalaba:

Por otra parte, usted, señor Presidente, utilizó la expresión "laicidad positiva" para designar esta comprensión más abierta. En este momento histórico, en el que las culturas se entrecruzan cada vez más entre ellas, estoy profundamente convencido de que es cada vez más necesaria una nueva reflexión sobre el significado auténtico y sobre la importancia de la laicidad. En efecto, es fundamental, por una parte, insistir en la distinción entre el ámbito político y el religioso para tutelar tanto la libertad religiosa de los ciudadanos como la responsabilidad del Estado hacia ellos; y, por otra parte, adquirir una conciencia más clara de la función insustituible de la religión para la formación de las conciencias, y de la contribución que puede aportar, junto a otras instancias, para la creación de un consenso ético de fondo en la sociedad. (Benedicto XVI, 2008)

El concepto de laicidad siguió muy presente en el discurso oficial de Benedicto XVI. Entre otras ocasiones, lo volvió a utilizar en el 2007 en Aparecida:

El respeto de una sana laicidad —incluso con la pluralidad de las posiciones políticas - es esencial en la tradición cristiana. Si la Iglesia comenzara a transformarse directamente en sujeto político, no haría más por los pobres y por la justicia, sino que haría menos, porque perdería su 
independencia y su autoridad moral, identificándose con una única vía política y con posiciones parciales opinables. La Iglesia es abogada de la justicia y de los pobres precisamente al no identificarse con los políticos ni con los intereses de partido. Sólo siendo independiente puede enseñar los grandes criterios y los valores inderogables, orientar las conciencias y ofrecer una opción de vida que va más allá del ámbito político. (Benedicto XVI, 2007)

En septiembre del 2010, se dio lo que se considera uno de los discursos más relevantes del Pontífice, en un Encuentro con representantes de la sociedad británica desarrollado en el Westminster Hall. Para ello, tomó como base la contemporaneidad del ejemplo dado en su momento por Tomás Moro, enfrentado a no contrariar a su soberano terrenal, pero al mismo tiempo, fiel a su conciencia, subrayaba, entre otras ideas centrales, lo siguiente:

Con todo, las cuestiones fundamentales en juego en la causa de Tomás Moro continúan presentándose hoy en términos que varían según las nuevas condiciones sociales. Cada generación, al tratar de progresar en el bien común, debe replantearse: ¿Qué exigencias pueden imponer los gobiernos a los ciudadanos de manera razonable? $\mathrm{Y}$ ¿qué alcance pueden tener? ¿En nombre de que autoridad pueden resolverse los dilemas morales? Estas cuestiones nos conducen directamente a la fundamentación ética de la vida civil. Si los principios éticos que sostienen el proceso democrático no se rigen por nada más sólido que el mero consenso social, entonces este proceso se presenta 
evidentemente frágil. Aquí reside el verdadero desafío para la democracia. (Benedicto XVI, 2010, pp. 3-4)

En estas ideas y convicciones descansa una forma de entender el mundo y la existencia humana. En la realidad, sigue siendo más que complicado el crear un verdadero ambiente de diálogo concreto entre fe y razón, entre fundamentos doctrinales y políticas públicas, entre moral y ética. La educación, la tecnología, la ciencia han adquirido nuevos ritmos y nuevas potencialidades. En el centro de todo, nuevamente, se encuentra el problema esencial de la humanidad y de su historia, problema de siempre, pero ahora pensado en los términos de los inicios del siglo XXI. Descristianización y laicidad no solo corresponden a un proceso histórico, quizás inconcluso, sino, posiblemente el preludio de una nueva situación en que las oposiciones Estado-Iglesia pueden dejar paso a nuevas y aún más conflictivas consideraciones sobre la existencia. Se trata de un debate complicado, pero siempre necesario.

\section{Algunas Consideraciones Finales}

A continuación, podemos concluir en algunas situaciones de acuerdo con lo expuesto anteriormente. En primer lugar, la relación religiosidad-Iglesia es un problema histórico que se expresa en términos de compromisos, adhesiones y particularmente en términos de actitudes y comportamientos. Desde ese punto de vista, aún cuando las explicaciones de la historia no superan en definitiva las interrogantes respecto a la naturaleza y trascendencia de la vida, se siguen generando conflictos entre el consciente y el inconsciente. Estos, generalmente, se resuelven a partir de instancias externas a los individuos. 
En segundo lugar, y a partir de ello, la cultura y diversas expresiones del poder orientan e influyen sobre la vida histórica de las personas, sin lograr superar sus naturales inclinaciones a pensarse más allá de su materialidad existencial. En lo que concierne a la propia historicidad, la modernidad observa estas situaciones a partir de fenómenos de larga duración como son la descristianización y la laicización. Particularmente, al menos en el mundo occidental, el Estado y la Iglesia han sido, y aún lo son, actores vitales en definir los términos en que las sociedades deben separar sus ámbitos de acuerdo con sus propios quehaceres. En una época de fuerte crecimiento de un nuevo liberalismo, Benedicto XVI ha prestado especial atención a esta situación.

En tercer lugar, en la propia vida moderna, tenemos un gran problema entre lo que son los ámbitos de la vida pública y de la vida privada. En las últimas décadas, por una parte, los avances de la vida pública nos hacen pensar que somos más libres que antes. Pero, por otra, ellos nos llevan a constatar que, en muchos sentidos, somos menos libres porque no se trata solo de las imposiciones del Estado. Se encuentra, también, la cultura dominante dentro de una sociedad que se ve amplificada a través de la TV, los medios de comunicación, entre otros.

Como resultado de lo anterior, es efectivo que la explicación del hecho histórico nos lleve a ciertos extremos y ello va creando unos ambientes armónicos entre la historia que queremos vivir y la historia que queremos proyectar. Pero también, por el contrario, lo que va sucediendo es que continuamente, de una u otra manera, cada explicación se va encerrando de tal modo que lo que se impone es simplemente lo que se escucha. Ello tiene mucho que ver con lo que podemos visualizar entre los límites de la tolerancia y la intolerancia. No solo hoy, lo podemos observar también en el pasado. Desde los no creyentes y desde los creyentes, uno de los aspectos más permanentes de la historia universal ha sido el de la intolerancia. Esto 
se debe a que, finalmente, la resolución del problema del hecho religioso ha sido una resolución que se explicita en términos históricos y ello siempre tiene que ver con el Poder, poder que aquí crea, más bien, intolerancia que tolerancia. En todo caso, cualquier forma de intolerancia no resuelve los problemas esenciales ni del hombre ni de la humanidad.

La única forma en que estas ideas dispersas concuerden en un punto donde todos estemos pensando, no en la misma respuesta o solución, pero sí en el mismo problema, es convertir, efectivamente, cada una de esas ideas en un problema de la vida religiosa que se tiene que entender desde la vida histórica. Es muy difícil, pero a la vez, muy apasionante. El problema de fondo es pensar, hoy, si estas relaciones entre Estado-Iglesia, siendo en algunos casos de mucha confrontación, en un futuro próximo serán más valorizadas respecto a otras formas de desarrollo científico-cultural que vienen apareciendo en escena. Despejar el pasado es una buena opción para enfrentar mejor el futuro. La laicidad positiva —en el que la religión no resta, sino suma - es un buen punto de partida. 


\section{Referencias}

Barrio, J. M. (2006). Antropología del hecho religioso. Madrid, España: Rialp. Benedicto XVI. (2007). Discurso de Apertura de la V Conferencia General del Episcopado Latinoamericano. Recuperado de www.aciprensa. com/aparecida07/disc13mayc.htm.

Benedicto XVI. (2008). Elogio de la laicidad positiva e invitación a los intelectuales. Un diálogo más abierto y positivo entre la Iglesia y el Estado. Visita oficial a Francia, 12 septiembre 2008. L'Osservatore Romano, (38), 5.

Benedicto XVI. (2010). Encuentro con Representantes de la Sociedad Británica. Discurso del Santo Padre Benedicto XVI. Westminster Hall, City of Westmisnter, 17 septiembre de 2010. L'Osservatore Romano, (39), 3-4.

Becker, M. (1997). When I was a Child, I Danced as a Child, But Now that I am Old, I Think about Salvation. Rethinking History: The Journal of Theory and Practice, 1(3), 343-355.

Cavieres, E. (1998). Psico-historia individual, mentalidades colectivas. Representaciones e Ideología. En Autor, Sociedad y mentalidad en perspectiva histórica (pp. 149-184). Eudeval,Valparaíso: Chile.

Chaunu, P. [1979] (1982). Historia y población. Un futuro sin porvenir. México D. F., México: Fondo de Cultura Económica.

Cifuentes, C. (25 de mayo de 2012). Estudio en 30 países muestra a Chile como el segundo que más cree en Dios. La Tercera. Recuperado de www.imocorp.com.mx/imo2/index.php/encuestas/difusion/menudifusion-encuestas-issp/176-publicacion-2016-15.

De Cesárea, E. (2008). Historia eclesiástica. Barcelona, España: Edición Clie. Fernández Pérez, A. \& Vaquero Iglesias, J. (noviembre de 1981-junio de 
1982). Reseña. Piedad barroca y descristianización. El Basilisco, (13), 85-86.

Le Goff, J. [1986] (1996). La bolsa y la vida. Economía y religión en la Edad Media. Barcelona, España: Gedisa Edit.

Sarkozy, N. (2007). Discurso de en el Palacio de Letrán, 20 diciembre 2007 (Trad. J. Sicilia). Recuperado de www.conspiratio.com.mx

Vovelle, M. [1982] (1985). Ideologías y mentalidades. Barcelona, España: Ariel.

Vovelle, M. (Ed.). [1992] (1995). El hombre de la Ilustración. Madrid, España: Alianza. 